Foraminifera to Quaternary climate in an article drawing extensively on work previously published elsewhere by himself and A. McIntyre. And W. N. Orr and D. G. Jenkins review planktonic Foraminiferal zonation schemes for the Caenozoic, partly in the light of selective solution problems. Throughout the volume the figures, whether line drawings or half-tones, are poorly reproduced; "excellent scanning electron micrographs" have been printed too dark to allow discrimination of detail, and print densities on other line drawings and half-tones are very variable. The plates associated with the article on Mesozoic Foraminifera are very wasteful of space.

Volume 2 contains a greater variety of contributions. Recent Caenozoic and Mesozoic Radiolaria are well reviewed in 142 pages by R. E. Casey, W. R. Riedel and A. Sanfilippo, and E. A. Pessagno. Recent and fossil calcareous nannoplankton are looked at from various points of view in 250 pages. Interesting aspects of the present biogeography and solution of the skeletal remains of coccoliths are dealt with by $\mathbf{S}$. Honjo, K. R. Geitzenauer et al. and N. Schneidermann respectively, and $\mathrm{W}$. W. Hay gives a very useful overall summary review of the stratigraphical development of the calcareous nannoplankton. Dinocysts, probably best known from marine epicontinental sediments, and the Silicoflagellates, a rather limited siliceous group, are reviewed by G. L. Williams and E. Martini respectively in a total of 114 pages. The remainder of the volume is given over to a discussion of automated biostratigraphy by T. R. Worsley and M. L. Jorgens, an account of the application of ${ }^{18} \mathrm{O}$ analysis to Quaternary microfossils by $\mathbf{J}$. van Donk, and a review by the editor himself of the palaeoceanographical interpretation of Caenozoic deep-sea sedimentation. Of these three articles the one on automated biostratigraphy raises some interesting philosophical points about what is being attempted in the process of palaeontological time correlation, without producing conviction that the proposed methods will ever become widely adopted. Van Donk's summary is by now only one of a number on this important topic available to the interested reader in other readily accessible journals or serial publications. Ramsay's own contribution systematically applies pictographic analysis of the results of the DSDP to the end of leg 40 in an endeavour to interpret variations in chemical and physical properties in the oceans during the Caenozoic. Most of his arguments depend on analogies and methods (back-tracking, hiatus analysis, CCD determination) developed by a number of previous authors, and a lack of discussion of the fundamental processes at work makes it difficult to evaluate satisfactorily the validity of the circulation patterns inferred.
It is difficult to know how to make an overall summary judgement of such an expensive book. At this price very few individuals, and only a handful of specialist institutions, are likely to buy it. Yet several of the contributions it contains have clearly involved a real labour of love in their preparation, and as such deserve consideration by a much wider audience than they are likely to get. It is a pity that incorporation of large and less widely interesting contributions has at least doubled and probably trebled the length and cost of copies of the total work. The situation is not helped by the poor quality of reproduction of the illustrations throughout, by rather numerous spelling and printing errors, and by patches of undisciplined grammar that make parts of some articles literally incomprehensible.

\section{Heavy rare earth metals}

The Electronic Structure of Rare-Earth Metals and Alloys: The Magnetic Heavy Rare-Earths. By B. Coqblin. Pp. 656. (Academic: New York, London and San Francisco, 1977.) £29.50; $\$ 57.75$.

A MAJOR contribution to the literature on the rare earth metals, this book provides an extensive and detailed survey of those properties of the heavy rare earth metals from gadolinium to thulium which arise from the unique magnetic structures found in these metals. In 650 pages, and with over 680 references to the orginal literature, Professor Coqblin not only summarises the experimental data but also presents accounts of the underlying theoretical aspects in some detail.

The first two chapters present a preliminary survey of the experimental data and basic theory relating to the magnetic properties of the heavy rare earth metals. Chapters 3 and 4 take up the detailed theoretical description from the point of view of molecular field theory and spin-wave theory, including in each case some anisotropy contribution but not at this stage including magnetoelastic effects. Chapter 5 returns to experimental data and presents in detail the results relevant to the spin-wave theory discussed in chapter 4. In chapter 6 the wave vector dependence of the exchange integral is discussed in relation to the Fermi surface. The modification of the Fermi surface arising in the helical magnetic phases, which give rise to superzones and provide an explantion for the temperature variation of the turn angle, is also explained. Magnetoelastic effects are surveyed in detail in chapter 7 , in which the author has
Oceanic micropalaeontology seems to be going through something of a publication crisis at the moment. An explosion of results is not finding altogether adequate means of expression, and seminal articles are appearing scattered through a wide literature. Several attempts have been made in recent years to bring together results in this field. None of them have been really successful and some have failed altogether. This contribution will be of some help to the interested reader seeking an overview, if he can get hold of a copy and if he is prepared to live with its transparent deficiencies.

B. M. Funnell

B. M. Funnell is Professor of Environmental Sciences at the University of East Anglia, Norwich, UK.

principally reviewed the role of magnetoelastic effects in driving magnetic phase transitions. It is in chapter 8 that the contribution of magnetoelastic effects to the spin-wave energy is set out in some detail in relation to neutron diffraction and magnetic resonance experiments. The final chapter presents a brief survey of band structure effects and transport properties.

There are two other books currently available to the research worker interested in the heavy rare earth metals which attempt to cover the whole field in some detail: Physics of Rare Earth Solids (Chapman and Hall: London, 1972) by K. N. R. Taylor and M. I. Darby is a wide-ranging review written at graduate level; Magnetic Properties of Rare Earth Metals (Plenum: New York, 1972) edited by R. J. Elliott, presents a series of monographs written by experts on particular aspects of the field. Coqblin's book provides a unified survey of the literature at advanced graduate level and complements the two other books. It will be welcomed by all research workers in the field and by those who have need to enquire about particular properties of the rare earth metals. However, those who do have need to use the book for specific reference should be warned that there is no survey of the crystallographical structures and metallography of the heavy rare earth metals and, much more regrettably, there is no survey of nuclear hyperfine interactions. Professor Coqblin has promised a further volume covering the other rare earth metals. We shall await this additional contribution with considerable confidence.

D. M. S. Bagguley

D. M. S. Bagguley is Lecturer in Physics at the Clarendon Laboratory, University of Oxford, UK. 